\title{
Integrating Circulating Tumor Cell Data with Imaging and Serum Prostate-Specific Antigen Measurement for Metastatic Prostate Cancer Therapy Management
}

\author{
Oscar Goodman ${ }^{a} \quad$ Eric R. Schuur ${ }^{\text {b, c }}$ \\ ${ }^{a}$ Comprehensive Cancer Centers of Nevada, Las Vegas, Nev., ${ }^{b}$ VMWA LLC, Palo Alto, Calif., \\ and ${ }^{\text {T}}$ The Jon Block Group, San Francisco, Calif., USA
}

\section{Key Words}

Decision making $\cdot$ Circulating tumor cells $\cdot$ Prostate cancer

\begin{abstract}
Optimal management of therapy can improve quality of life, and potentially survival, of patients with metastatic prostate cancer. Circulating tumor cell (CTC) enumeration in the peripheral blood holds promise for facilitating optimal therapy management based on high cancer specificity and prompt response to changes in disease status. We present the case of a 54-year-old male diagnosed with metastatic prostate cancer. The patient's disease status was monitored radiographically and by serial determinations of serum prostate-specific antigen concentration, performance status, and CTC enumeration. At multiple visits, the disease status was not clear due to discordance between standard assessments. The additional information provided by CTC enumeration helped clarify disease status and provided support for treatment decisions.

(c) 2014 S. Karger AG, Basel
\end{abstract}

\section{Introduction}

Metastatic castration-resistant prostate cancer (mCRPC) is uniformly fatal: in 2008, more than a quarter of a million deaths worldwide were attributed to this disease [1]. 
Nevertheless, progress has been made in extending the survival and improving the quality of life of men with mCRPC as improved therapies have become available [2,3]. These improvements have been guided by a limited number of tools (imaging, serum tumor markers, and clinical signs and symptoms) for ongoing assessment of mCRPC. Additional tools that can contribute to accurate and timely measurement of disease status would improve patient care, quality of life, and potentially survival.

Circulating tumor cells (CTCs) are rare cells that can be found in the peripheral blood of patients with many different types of cancer, but not in healthy controls [4]. Numerous prospective studies have demonstrated their prognostic utility in prostate and other cancers [4]. Patients with $\geq 5$ CTCs $/ 7.5 \mathrm{ml}$ of peripheral blood have been shown to have a shorter time to relapse and a shorter survival time than patients with $<5$ CTCs/7.5 $\mathrm{ml}[5,6]$. In addition, certain properties of CTCs, such as high specificity for malignant disease [7] and prompt changes in concentration with changes in disease state [8], may lend themselves to accurate evaluation of metastatic disease status. An analytically validated test cleared by the United States Food and Drug Administration is commercially available for enumeration of CTCs in metastatic prostate cancer (CELLSEARCH ${ }^{\circledR}$, Janssen Diagnostics, LLC; Raritan, N.J., USA).

One challenge to integrating any new assessment into patient care is determining the optimum use of the information provided by that assessment. Here, we discuss the application of CTC enumeration to assist in the monitoring of the disease status of a patient with metastatic prostate cancer in conjunction with preexisting tests to illustrate how CTC information might be useful in the clinical setting.

\section{Case Presentation}

The patient was a 54-year-old male with a 6-month history of hip discomfort. Imaging was ordered and lumbosacral films demonstrated multiple rounded and sclerotic foci over the visualized bony pelvis, which were considered suspicious for metastatic prostate cancer. The patient's prostate-specific antigen (PSA) level was $34.2 \mathrm{ng} / \mathrm{ml}$. Based on these findings, the patient was referred for a prostate biopsy. The biopsy revealed prostate adenocarcinoma with a Gleason score of $7(3+4)$ involving all cores from the right side.

The patient was treated with complete androgen blockade. His PSA level reached a nadir of $3.6 \mathrm{ng} / \mathrm{ml}$ after approximately 3 months of therapy, after which it began to rise. By the sixth month of therapy, the patient's PSA had risen to $16 \mathrm{ng} / \mathrm{ml}$ (fig. 1). An initial CTC measurement taken at this time returned a value of $36 \mathrm{CTCs} / 7.5 \mathrm{ml}$ of peripheral blood using the CELLSEARCH system.

Based on the elevated PSA and CTC levels as well as progression of pain due to osseous metastatic disease, the patient was placed in a clinical trial of docetaxel plus bevacizumab therapy. After 3 cycles of treatment (approximately 8 months after initial diagnosis) the patient's CTC level had risen to $145 \mathrm{CTCs} / 7.5 \mathrm{ml}$, while the PSA level dropped to $2.3 \mathrm{ng} / \mathrm{ml}$. Computed tomography (CT) imaging demonstrated stable disease. At approximately 11 months after diagnosis, the patient's PSA level had dropped to $1.0 \mathrm{ng} / \mathrm{ml}$ and his CTC level had dropped to $13 \mathrm{CTCs} / 7.5 \mathrm{ml}$. Clinically, the patient reported worsening pain, which was attributed to diffuse osteoblastic metastases. CT imaging revealed progressive disease with nodal involvement. The patient was switched to oral cyclophosphamide.

Within 1 month of initiating the new therapy, the patient reported that his pain was lessened. By 13 months after diagnosis, the CTC level had reached zero, while the PSA level increased to $3.4 \mathrm{ng} / \mathrm{ml}$. After 16 months of therapy, the CTC level was $2.0 \mathrm{CTCs} / 7.5 \mathrm{ml}$ and 
his circulating PSA level had fallen to $1.8 \mathrm{ng} / \mathrm{ml}$; CT imaging showed a partial response. The patient continued on cyclophosphamide treatment for an additional 4 months, during which time both CTC and PSA levels slowly increased. By 19 months after diagnosis, his CTC level had risen to 5 CTCs $/ 7.5 \mathrm{ml}$, while his PSA level was $2.4 \mathrm{ng} / \mathrm{ml}$. Although CT imaging at this time showed stable disease, the patient reported an increase in pain. Considering the increasing pain and elevated CTC concentration as evidence of progression, cyclophosphamide treatment was discontinued and alternative treatment through clinical trials was pursued as a possible avenue for this patient.

\section{Discussion}

Two assessments commonly used in MCRPC, imaging and PSA concentration, are known to have properties that in some situations may reduce confidence in disease assessment [9]. Bony lesions frequently occur in MCRPC; however, CT imaging, radionuclide imaging, or other imaging modes often do not reveal responses to treatment in a timely fashion. Frequently, 2 rounds of imaging and 3 or more months of observation are needed to determine if there is progression or response to therapy. PSA levels are frequently unrelated to disease status due to factors such as previous therapy and tumor grade. In addition, both of these assessments are subject to 'flare' phenomena that can mask a response to therapy $[10,11]$. When few assessment options are available, discordance between them can diminish confidence in treatment decision making [3].

CTCs have been shown in multiple prospective studies to be prognostic of both diseasefree survival and overall survival in mCRPC [4]. In a manner similar to that described by others, this case illustrates how the prognostic value of the measured CTC concentration in the peripheral circulation can help resolve assessment discrepancies and increase confidence in treatment decisions [12].

In the first instance, after 6 cycles of docetaxel plus bevacizumab, this patient's PSA level had dropped from 16.1 to $1.0 \mathrm{ng} / \mathrm{ml}$, suggesting a therapeutic response. However, the patient reported worsening pain which suggested the possibility of disease progression. His CTC level was measured at $13 \mathrm{CTCs} / 7.5 \mathrm{ml}$, well above the $5 \mathrm{CTCs} / 7.5 \mathrm{ml}$ cutoff for poor prognosis mCRPC. The increasing pain and elevated CTC level prompted repeat imaging, which confirmed new nodal disease and progression. On this basis, the patient's therapy was switched to cyclophosphamide. Subsequently, the patient's CTC level diminished to zero, his pain resolved, and imaging 5 months later demonstrated a partial response. The decision was ultimately based on the specificity of CTCs for malignant disease and the high prognostic value of CTCs in mCRPC.

Subsequently, 19 months into treatment the patient again reported worsening pain, although imaging suggested stable disease. The patient's PSA concentration had stayed consistently low, ranging from 1.0 to $3.4 \mathrm{ng} / \mathrm{ml}$. The patient's CTC level, however, was measured at $5 \mathrm{CTCs} / 7.5 \mathrm{ml}$, which supported the conclusion that the patient's disease was progressing on cyclophosphamide therapy despite his low PSA concentration. The decision was made to discontinue cyclophosphamide and evaluate clinical trial options for the patient.

Metastatic prostate cancer is difficult to evaluate, and therefore treatment decisions are challenging. The two most frequently used evaluation methods, imaging and PSA level, in some cases do not yield a clear answer on disease status and prognosis and are often discordant. This case illustrates how CTC enumeration, with information properties that 
complement other assessments, can compensate for some of the inconsistencies of other evaluation methods, thereby improving confidence in treatment decisions.

\section{References}

1 International Agency for Research on Cancer: GLOBOCAN 2008. Estimated cancer incidence, mortality, prevalence and disability-adjusted life years (DALYs) worldwide in 2008. http://globocan.iarc.fr/ (accessed December 12, 2013).

2 National Cancer Institute: SEER Stat Fact Sheets. Prostate cancer. http://seer.cancer.gov/statfacts/html/prost.html (accessed November 27, 2013).

3 Zelefsky MJ, Eastham JA, Sartor AO: Cancer of the prostate; in Devita VT, Lawrence TS, Rosenberg SA (eds): Cancer: Principles and Practice of Oncology. Lippencott Williams \& Wilkins, Philadelphia, 2011, pp 12201271.

4 Hayes DF, Smerage JB: Circulating tumor cells. Prog Mol Biol Transl Sci 2010;95:95-112.

5 Danila DC, Heller G, Gignac GA, Gonzalez-Espinoza R, Anand A, Tanaka E, Lilja H, Schwartz L, Larson S, Fleisher M, Scher HI: Circulating tumor cell number and prognosis in progressive castration-resistant prostate cancer. Clin Cancer Res 2007;13:7053-7058.

-6 Scher HI, Jia X, De Bono JS, Fleisher M, Pienta KJ, Raghavan D, Heller G: Circulating tumour cells as prognostic markers in progressive, castration-resistant prostate cancer: a reanalysis of IMMC38 trial data. Lancet Oncol 2009;10:233-239.

-7 Allard WJ, Matera J, Miller MC, Repollet M, Connelly MC, Rao C, Tibbe AG, Uhr JW, Terstappen LW: Tumor cells circulate in the peripheral blood of all major carcinomas but not in healthy subjects or patients with nonmalignant diseases. Clin Cancer Res 2004;10:6897-6904.

8 Budd GT, Cristofanilli M, Ellis MJ, Stopeck A, Borden E, Miller MC, Matera J, Repollet M, Doyle GV, Terstappen LW, Hayes DF: Circulating tumor cells versus imaging - predicting overall survival in metastatic breast cancer. Clin Cancer Res 2006;12:6403-6409.

-9 Scher HI, Warren M, Heller G: The association between measures of progression and survival in castratemetastatic prostate cancer. Clin Cancer Res 2007;13:1488-1492.

$\checkmark 10$ Messiou C, Cook G, Desouza NM: Imaging metastatic bone disease from carcinoma of the prostate. $\mathrm{Br}$ J Cancer 2009;101:1225-1232.

$\checkmark 11$ Nelius T, Filleur S: PSA surge/flare-up in patients with castration-refractory prostate cancer during the initial phase of chemotherapy. Prostate 2009;69:1802-1807.

12 Hayes DF, Smerage J: Is there a role for circulating tumor cells in the management of breast cancer? Clin Cancer Res 2008;14:3646-3650. 


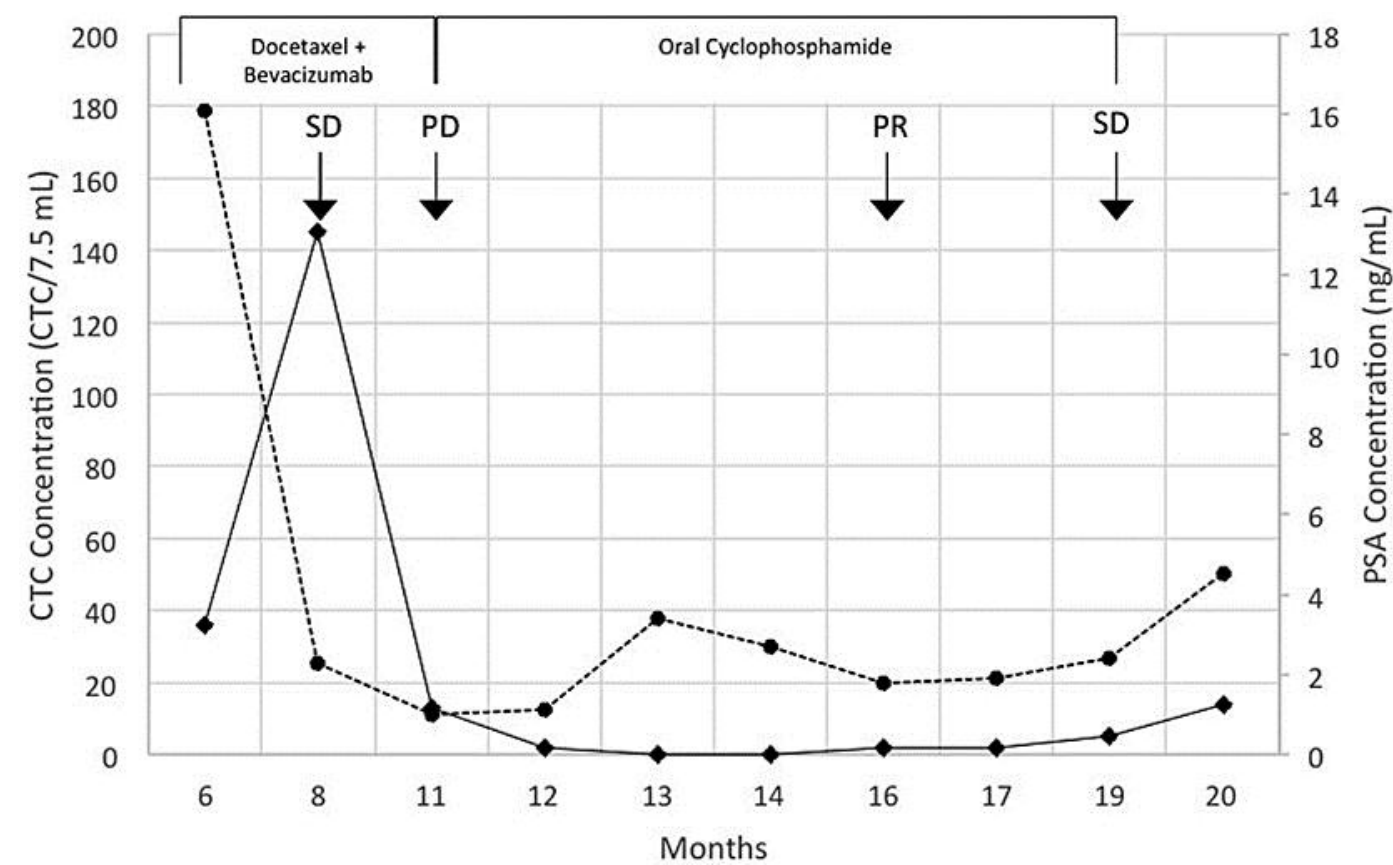

Fig. 1. Integrated display of assessments performed. The values for the various assessments used in managing this case are displayed above the time line for treatment in this case. Each symbol represents an assessment. Diamonds = CTC count; squares = PSA determinations. The left-hand axis displays the scale for CTC values; the right-hand axis displays the scale for PSA values. The time point of each CT imaging assessment is shown as a 2-letter code with an arrow below: $\mathrm{SD}=$ stable disease; $\mathrm{PD}=$ progressive disease; PR = partial response. Assessment dates are displayed across the horizontal axis. Bars representing the duration of each treatment are shown across the top of the graph with the name of the therapeutic regimen in the box. 